\title{
MITS VINDT ZICHZELF OPNIEUW UIT HET GELEXICALISEERDE JA, MITS ALS NIEUWE GEBRUIKSVORM
}

\author{
GERT LOOSEN
}

\begin{abstract}
Mits becoming popular once more: lexicalized ja, mits as a new grammatical construction

Grammar and style books restrain the use of mits to a few grammatical constructions. Language users do not care about those restrictions and tend to vary, but always in respect to the semantic regularity described by Saskia Daalder: mits $\mathrm{p}, \mathrm{q}$ (with $\mathrm{q}=$ the desired status for which $\mathrm{p}=$ conditio sine qua non). A new mits-construction arises in the twentieth century: the lexicalised $J a$, mits.
\end{abstract}

Key words: mits; if; preposition; conjunction; lexicalisation

\section{Inleiding}

Peter Burger $(1995,1996,1997)$ schreef drie artikelen met als titel 'Gaten in de taal' in het maandblad Onze Taal waarin het gaat het om begrippen waarvoor we een buitenlands woord gebruiken, én om fenomenen waar we (nog) helemaal geen woord voor hebben en waarbij we ons moeten behelpen met omschrijvingen. Het maandblad maakte er een heuse rubriek van enkele jaren later. Het merendeel van de woorden in het Nederlands omschrijft dingen, gevoelens, situaties met een duidelijke lexicale betekenis. Mits verdient in anderstalige lijstjes van dien aard ook zijn plaats. Vertalers hebben geen probleem om in hun respectieve doeltalen mits te omschrijven, maar toch betwijfel ik of provided that, si/pourvu que, vorausgesetzt dass enz. helemaal de 'semantische regelmaat' dekken die Daalder (2007) bij mits ontwaarde:

"[...] een constructie $\mathrm{q}$, mits $\mathrm{p}$ is gekoppeld aan deze inhoudelijke karakteristiek: voor de realisering van wenselijkheid q vormt vervulling van conditie p een strikte voorwaarde." (2007: 404)

Gebruik en beoordeling van mits in het Nederlands blijken vragen op te roepen. We zouden de discrepanties tussen de meningen van beschrijvers (grammatica's) en voorschrijvers (stijlgidsen, taaltuiniers) enerzijds en de concrete verschijningsvormen van 
mits bij taalgebruikers anderzijds in drie contradicties kunnen vatten. In wat volgt gaan we kort in op die tegenstrijdigheden waarbij we de derde wat uitvoeriger bekijken.

\section{Eerste contradictie}

De ANS trekt een duidelijke lijn tussen aanvaarde (conjunctie) en niet-aanvaarde (conjunctie en prepositie) gebruiksvormen van mits, maar de taalgebruiker leeft zich onbekommerd uit in een breed continuüm dat begrensd wordt door mits als conjunctie en mits als prepositie. De eerste voorbeeldzin met mits in de e-ANS zien we in (1).

(1) Ik zal hiermee doorgaan, mits iedereen met deze werkverdeling akkoord gaat. (E-ANS 10-3-8-2-(5))

Hier wordt de voorwaarde $\mathrm{p}$ keurig door een bijzin uitgedrukt, ingeleid door het voegwoord mits. Als het onderwerp van de voorwaardelijke bijzin p gelijk is aan dat van wenselijkheid q, dan kan de bijzin zonder probleem zonder onderwerp en persoonsvorm geconstrueerd worden. Zie (2).

(2) Brieven kunnen, mits voldoende gefrankeerd, op de postkamer worden afgegeven. (= mits de brieven voldoende gefrankeerd zijn) (E-ANS 10-3-8-4-(16))

Volgens de e-ANS geldt dit tevens voor de voegwoorden indien, zo en tenzij maar er worden geen voorbeelden gegeven. Taaladvies.net - net als de ANS onder auspiciën van de Taalunie - is strenger (of gewoon vollediger, resp. preciezer?) dan de ANS:

"Na mits kan ook een beknopte bijzin voorkomen, geconstrueerd met een voltooid deelwoord." (eigen cursivering)

Vallen dus uit de boot: een beknopte bijzin geconstrueerd met een onvoltooid deelwoord ${ }^{1}$ (mits voldoende frankerend) of met te + infinitief (mits voldoende te frankeren), mits gevolgd door een deverbaal substantief (mits voldoende frankering) of zelfstandignaamwoordgroep (mits voldoende postzegels). Voor Taaladvies zijn deze combinaties 1 . geen standaardtaal en 2. Belgisch. We geven hier de voorbeeldzinnen die Taaladvies voor de respectieve constructies aanhaalt (herkenbaar door de zeer nadrukkelijke markering "(in België, geen standaardtaal)"), telkens gevolgd door zinnen die op dezelfde manier zijn opgebouwd en die we zonder veel moeite vonden op Nederlandse websites.

1 Hoewel deze constructie ooit heel gewoon was in het Nederlands en door de taalgebruikers nog steeds gebruikt wordt, veroordeelt ook de ANS het gebruik ervan. Thijs doet onderzoek naar deze constructie in de 17 de eeuw: "“mits.pp”, een syntactische configuratie2 in het Vroegnieuwnederlands waarin het voegwoord mits zinsverkortend gevolgd wordt door een participium presentis (vanaf nu: pp), ook wel aangeduid als: een pp-constructie versterkt met het voegwoord mits. Even opmerkelijk als het feit dat deze constructie in modern Nederlands nauwelijks meer voorkomt is de constatering dat zij in vergelijking met voegwoordelijk versterkte pp-constructies met als en hoewel lange tijd dienst heeft gedaan: van ongeveer 1450 tot minstens 1700; in bepaalde tekstsoorten en gecombineerd met specifieke werkwoorden zelfs tot in 19de eeuw." (Thijs 2017: 1) 
(3) Mits hardwerkend kan hij voor het examen slagen. (in België, geen standaardtaal)

(3a) Bestuur is gezamenlijk verantwoordelijk, mits handelend naar eer en geweten. (Protestantse Kerk 2016)

(3b)Het zal een ieder vrij staan de te ladene en geloste goederen op dit Hoofd te bergen of te plaatsen, mits zorgende, dat de passage voor andere Vaartuigen of naar den Veerdam niet gehinderd worde [...] (Anon. 1807: 124)

(4) De bestelling wordt uitgevoerd, mits betaling na 8 dagen. (in België, geen standaardtaal)

(4a) Gedeeltelijk protest is slechts geldig mits betaling van het niet-betwiste gedeelte. (C\&P Furniture)

(5) Mits wat geluk kan de belegger mooie winsten boeken. (in België, geen standaardtaal)

(5a) Mits wat meer behendigheid ben je klaar voor een echte Ardennenrit bezaaid met stenen, wortels, pittige afdalingen en stevige klimpartijen. (Lips 2015)

(6) Mits het personeel efficiënter te plaatsen, kan er worden bespaard. (in België, geen standaardtaal)

(6a) Het vermogen wordt niet tot box 3 gerekend ( voorwaarden). (Anon. 2012)

Conclusie: mits leidt een voorwaarde in die geconstrueerd kan worden als een volwaardige bijzin, als een onvolledige of beknopte bijzin, of met een (heel vaak deverbaal) substantief. De taalgebruikers bedienen zich van dit hele continuüm en bekommeren zich daarbij niet om wat al dan niet als standaardtaal aanvaard wordt.

\section{Tweede contradictie}

Mits wordt vaker geschreven dan uitgesproken, maar beperkt zijn biotoop niet tot formelere teksten. Ook al zijn voorzetselconstructies met mits in Vlaanderen legio, De Taaltelefoon van de Vlaamse Overheid stelt:

"Mits is een onderschikkend voegwoord met de betekenis 'op voorwaarde dat', 'indien."

Wat het register betreft, wordt opgemerkt:

"Mits is een formeel woord dat vooral in geschreven taal voorkomt. Meestal kunt u een gewoner synoniem gebruiken: als ... (tenminste), op voorwaarde dat, voor zover, alleen als." (Taaltelefoon, s.d.)

Hier worden twee eigenschappen aangehaald die niet noodzakelijkerwijze naar hetzelfde gebruik van mits hoeven te verwijzen. Alhoewel we bij het schrijven van dit artikel nog geen toegang hadden tot het Corpus Gesproken Nederlands en evenmin tot het Corpus Hedendaags Nederlands, gaan we er vooralsnog van uit dat mits vaker geschreven dan gesproken voorkomt. Of het zich in geschreven teksten dan echter beperkt tot formele contexten, is nog maar de vraag. 
Wablieft - Centrum voor Duidelijke Taal geeft kranten en boeken uit in duidelijke taal, herschrijft teksten en verzorgt trainingen over duidelijke taal. Op die manier verlaagt deze organisatie de leesdrempel voor laaggeletterden ${ }^{2}$. Mits komt op de website (en in het online archief) van Wablieft helemaal niet voor. Er wordt allicht bewust rekening gehouden met de gangbare opvatting dat mits in formele en dus te vermijden constructies gebruikt wordt. Maar Het Laatste Nieuws, de traditionele Vlaamse krant met de meeste (meer dan 2 miljoen lezers) en de meeste laaggeletterde krantenlezers, en de minste nieuwswaarde (Stouthuysen 1999) sinds haar tabloidisering vanaf 1988 (D'hulster 2010), gebruikt mits complexloos: 50 keer tussen 15 mei en 15 juni 2018. In diezelfde tijdspanne gebruikt De Standaard (Vlaamse kwaliteitskrant met 650.000 lezers, de gemiddelde lezer is een hoogopgeleide Antwerpenaar van middelbare leeftijd (Cocquyt 2003, gebaseerd op cijfers van het Centrum voor Informatie over de Media)) gebruikt maar 29 keer mits.

Conclusie: mits komt niet voor in Wablieft dat duidelijk en eenvoudig taalgebruik als core business heeft en het als formeel bestempelde mits liever vermijdt. De Standaard is een kwaliteitskrant gericht op hoger opgeleiden en hanteert daarom een formelere taal dan de sensatiekrant HLN. Beide gebruiken echter vaak mits, en bij een kleine steekproef - hoe vaak wordt mits in de twee kranten gebruikt in de maand voorafgaand aan het schrijven van dit artikel? - bleek HLN zelfs vaker mits te gebruiken dan DS.

\section{Derde contradictie}

Mits zou verouderd zijn. Het is inderdaad oud, maar beleeft kennelijk een zoveelste leven: in de $20^{\text {ste }}$ eeuw komt er namelijk nog een verschijningsvorm bij: het gelexicaliseerde Ja, mits.

Naast de hierboven besproken en vandaag als standaardtaal (niet) aanvaarde gebruiksvormen van mits, blijkt het eeuwenoude woordje er in de laatste eeuw nog een stuk of twee bij te hebben ontwikkeld: Ja, mits $p$, en daaruit: Ja, mits. ${ }^{3}$ Deze nieuwe gebruiksvormen bewaren nog steeds de semantische regelmaat die Daalder onderkende, maar versterken een retorische dynamiek in hoofdzakelijk persuasieve teksten. Ja, mits. als uitdrukking wordt zelfs iconisch, als werktuig en handelsmerk van de discussiant.

Daalder (2006) onderscheidt drie syntactische verschijningsvormen in mits-constructies. De semantische regelmaat die deze mits-constructies laten zien kunnen we als volgt samenvatten. Een mits-constructie heeft een van de volgende vormen:

(a) $\mathrm{q}$, mits $\mathrm{p}$

(b) mits p, q

(c) q eerste deel, mits $\mathrm{p}$, q tweede deel

2 En duidelijkheid is nodig, want “[é]én op vijf Vlamingen heeft moeilijkheden om teksten te lezen. Eén op vier Vlamingen haakt af als lezen iets meer moeite kost. Eén op zeven Vlamingen is laaggeletterd. Zij hebben problemen met teksten lezen op papier en op websites. [...] Tel hierbij op dat veel teksten moeilijke woorden en ingewikkelde zinnen bevatten. Brieven van overheden en van organisaties, websites, folders ... Veel mensen lezen niet verder, omdat de teksten te moeilijk zijn." (http://www .wablieft.be).

3 Daarenboven ook als substantief, meestal in het paar mitsen en maren, maar deze vorm bespreken we in dit artikel niet. GL. 
Het deel q benoemt daarbij steeds een bepaalde wenselijkheid die bestaat volgens degene aan wie de verantwoordelijkheid voor de mits-constructie wordt toegeschreven (spreker, schrijver, bekend-gevende instantie; of de gedachtewereld van een talig geïntroduceerd karakter). Het deel p benoemt een strikte voorwaarde die volgens dezelfde persoon of instantie bestaat voor de realisering van de wenselijkheid in kwestie (Daalder 2007, Loosen 2017). Zie een voorbeeld onder (7).

(7) Een rustig, licht januarigerecht: een omelet met ui en tomaat. Zeer lekker [= q], mits goed gedaan [= mits p] (Volkskrant, 4-1-2007)

Zeer lekker bevestigt in q een bestaande wens dat ook het zeer eenvoudige gerecht van omelet met ui en tomaat goed zal aankomen bij de disgenoten. Maar die wens kan alleen gerealiseerd worden, zo zegt het citaat in de mits-frase, bij vervulling van de voorwaarde dat het gerecht goed gedaan is. (Daalder 2007).

Mits laat het daar echter niet bij. Kijken we naar de zogenaamde retorische vraag, ook wel interrogatio of schijnvraag genoemd:

"De spreker of schrijver verlangt geen antwoord, maar gebruikt de vraagvorm om meer nadruk op het gezegde te leggen of om zijn publiek aan het nadenken te zetten. Bijvoorbeeld: 'Zijn wij geen broeders?' (i.p.v.: 'Wij zijn toch broeders!').' (Bork 2012: 'retorische vraag')

Een aardige variant ontstaat nu, wanneer in een betogende tekst het antwoord op een gestelde vraag - uiteraard, zo lijkt het - bevestigend is, maar toch meer nuance behoeft en het daarom de vorm krijgt $J a$, mits $p$. Vormelijk suggereert de spreker met de vraag een dialoog met de tegenpartij aan te gaan en inhoudelijk met het antwoord in de vorm $J a$, mits $p$ een toenadering tot het standpunt van de tegenpartij, zonder echter gezichtsverlies te lijden: hij verlaat immers zijn eigen mening niet, maar brengt er een nuance in aan, waardoor hij een compromis lijkt na te streven.

Tot nog toe is er geen apart onderzoek gedaan naar $J a$, mits $p$, maar dat verdient het wel: een eenvoudige Google-zoekopdracht levert wel bijna honderdduizend treffers op. De constructie verschijnt op twee manieren. De eerste stap in deze evolutie is wanneer $\mathrm{q}$ als impliciet wordt voorgesteld of aangehaald in een voorgaande quasi-retorische vraag en daarom uit de constructie "q, mits p" verdwijnt. De voorwaarde p kan ook hier weer op verschillende manieren syntactisch uitgedrukt worden (zie de paragrafen 2 en 3 ). De tweede stap is wanneer $J a$, mits (dus zonder p en zonder q, maar dan toch nog met een variatie: "Ja, mits, nee, tenzij") gelexicaliseerd wordt. Eerst enkele voorbeelden met Ja, mits $p$ in (8)-(14).

(8) Mag men over het erf van zijn' buurman ook, door vensters of lichten, regtstreeks uitzigt hebben? Ja, mits de muur een' afstand van 20 palmen van dat erf heeft. (Leefkens 1840: 41)

(9) Ja, Trump kan winnen mits hij het spel heel slim speelt. (Ramdharie 2015)

(10) Mag een fabrikant/leverancier aanbevolen prijzen gebruiken? Ja, mits hij er niets aan doet om die aanbevolen prijzen ook af te dwingen. (Bogaerts 2018) 
(11) (Puff) Goed, goed, zustertje; wy zyn nu met de zaak van onze lotje bezig: is liet met uw genoegen dat de Heer schultz om acces komt vraagen? (Mev.v. d. b.) „Ja, mits dat lotje, welke - „voor haare heimelyke hardnekkigheid eene kleine penitentie verdient, my om dit verlof komt vraagen. (Hermes 1779: 410)

(12) Wellicht kan daarom op de vraag: "Is de bibliotheek toegankelijk", het best geantwoord worden: "Ja, mits na schriftelijke aanvrage, en vermelding, van het doel van het bezoek”. (Anon. 1913)

(13) Hierop vroeg de president rond, of men hem zoude vrijstellen. Het algemeene antwoord was: "Ja, mits bekennen." (Van Schelven 1912)

(14) Plotseling vroeg hij: “Zou ik een uitstapje mogen maken?" "Ja, mits niet ver." (Hoogenbirk 1922).

Vervolgens een aantal data met $J a$, mits onder (15)-(19).

(15) “Ik zou het liefst 'ja, mits' stemmen. Voor 'nee' kies ik niet”' (Beek 2018)

(16) 'Ja, mits' bij uitbreiding in Overijssel. (Rossum 2017)

(17) De 'Ja, mits'-cultuur toetsen aan de hand van een casus. (Anon. 2017)

(18) Ja mits (Wijck 2017)

(19) Nu komen zij met een nog geniepiger opzet: zij zullen het hongerende Nederlandsche volk "toestaan", dat enkele treinen per week voedsel brengen, mits... Ja, mits! Mits wijzelf helpen de spoorwegstaking te breken! (Anon. 1945)

Ten slotte drie voorbeelden met Ja, mits, nee, tenzij in (20)-(21).

(20) Doden van dieren: ja, mits ..., of nee, tenzij ...? (Stassen 2011)

(21) Van ja mits naar nee tenzij (Sommer 2010)

(22) Tussen nee tenzij en ja mits (Kranenburg 1999)

$J a$, mits $p$ heeft niet altijd bestaan, maar komt toch al wel een paar honderd jaar voor in het Nederlands. De oudste attestatie die we gevonden hebben, komt uit het zesde boek van Sophia's reize van Memel naar Saxen, de vertaling van een Duits werk op het einde van de $18^{\text {de }}$ eeuw (het zal ook interessant zijn om na te gaan welke constructie in het 'Hoogduitsch' met $j a$, mits vertaald werd).

De meeste oude zinnen die we aantroffen, hebben een keurige voorwaardelijke bijzin mits $\mathrm{p}$, al zijn er enkele variaties in de vorm van zeer elliptische constructies, zoals in (12)-(14).

Dan komt het moment dat de stap wordt gezet naar een verzelfstandigd Ja, mits. Niet langer uit de zin, maar uit de context blijkt telkens welke wenselijkheid q nagestreefd wordt wanneer de absolute voorwaarde $\mathrm{p}$ daarvoor vervuld is. Deze gelexicaliseerde constructie doet het in zijn kernachtigheid natuurlijk erg goed in krantenkoppen en andere titels. Het is een haast iconische uitdrukking in een overlegcultuur waar verschillende partijen stevig voor hun eigen mening uitkomen, maar uiteindelijk streven naar consensus of compromis. Ja, mits illustreert dan de toenadering die een van de betrokkenen alvast wil doen: $J A=$ instemming met het standpunt van de tegenstander, komma 
MITS $=$ toch nog even eigen verwachtingen formuleren die als conditiones sine qua non gelden vooraleer tot een volmondig JA wordt overgegaan.

Voorlopig hebben we als oudste attestatie van Ja, mits. een historisch pareltje gevonden: een artikel uit de Nederlandse krant Ons Volk - het Vaderland ghetrouwe uit 1945, waarin gefulmineerd wordt tegen de onbetrouwbaarheid van de Duitse bezetter. Het gaat om (23) die we hier ter illustratie nogmaals geven, maar met wat meer context. Zie (23).

(23) De vos verliest wel zijn haren, maar niet zijn streken! Telkens en telkens weer hebben de nazi's met deze streken geprobeerd ons beet te nemen. Het laatste nog met de fuikpapiertjes, de Ausweise. Die actie is grootendeels mislukt: het meerendeel der werkgevers en de departementen hebben besloten geen Ausweise aan te vragen.

Nu komen zij met een nog geniepiger opzet: zij zullen het hongerende Nederlandsche volk "toestaan", dat enkele treinen per week voedsel brengen, mits... Ja, mits! Mits wijzelf helpen de spoorwegstaking te breken. Er is haast! De treinen moeten loopen. Er moet nog geroofd worden, troepen en munitie moeten vervoerd worden, het spoorwegpersoneel kan ook in Duitschland goede diensten bewijzen. (Anon. 1945)

Het geïsoleerde $J a$, mits! wordt hier nog niet gebruikt om stilaan het rabiate eigen standpunt te verlaten en al een toegeving aan de tegenstander te doen, maar om de verontwaardiging voor de voorwaarde die de Duitsers stellen lucht te geven. Het puntige en het exclamatieve van de gelexicaliseerde constructie is echter al wel aanwezig.

Als pendant met hetzelfde mechanisme, maar vertrekkend vanuit een aanvankelijk negatief antwoord, is er daarenboven Nee, tenzij. De combinatie van beide uitdrukkingen kan heel mooi genuanceerde meningen van voor- en tegenstanders uitdrukken. Zie (19). Zie tevens (20) waar sprake is van een ideologische verschuiving door een politicus die zijn huik naar de wind hangt.

$J a$, mits wordt op deze manier een werktuig en handelskenmerk van de discussiant. De jezuïeten hebben een eeuwenoude traditie in retorica - zeg maar argumenteren en retorische trucs. De Nederlandse columnist Theodor Holman, geboren in 1953, deed retorica (hier in de betekenis: de hoogste (zesde) klas van het gymnasium op rooms-katholieke scholen) vermoedelijk in 1970. Hij schreef ooit in Het Parool een hilarisch stukje over "heel prettige leraren [bij ons op de jezuïetenschool] van wie we toch heel wat hebben opgestoken". Er volgt ten slotte een lang citaat dat op hilarische wijze de overtuigende kracht van het jonge, gelexicaliseerde "Ja, mits." illustreert, ontstaan in een samenleving die alsmaar democratischer aan het worden was en waar dus meer geparticipeerd en gediscussieerd werd om tot compromissen te komen. Zie (24).

(24) Zo herinner ik me pater Lubbers s.j. Hij gaf Jezuïtische politieke retorica. "Pater Lubbers," vroegen wij wel eens, "stel, we hebben een standpunt ingenomen, maar wij willen dat veranderen, zonder dat te erkennen. Kunt u ons raad geven hoe je dat doet?" “Jongens, luister," zei Lubbers dan. "Als je van standpunt verandert, kun je zeggen: Mijn standpunt heeft zich ontwikkeld van 'ja, mits' tot 'neen, tenzij'. Zien jullie dat ik het woord 'ontwikkeld' gebruik? Dat is beter dan 'veranderd'. Wij veranderen niet, wij worden wijzer, dus 'ontwikkelen' wij onszelf.' 
"Maar pater Lubbers," zei een van ons, "ja, mits of nee, tenzij, dat is toch eigenlijk hetzelfde?"

“Ja, en nee”, antwoordde Pater Lubbers sj. En hij vervolgde: "Als ik vraag: 'Maria, wilt gij een versnapering?' En Maria antwoordt: 'Ja, pater, mits het een lekkere versnapering is', dan zegt Maria heel iets anders dan wanneer ze zegt: 'Neen, pater, tenzij het geen lekkere versnapering is.' Het ene is 'op voorwaarde', het andere betekent 'behalve als."

"Pater," zeiden wij toen, "we begrijpen het niet. In beide gevallen krijgt Maria toch die versnapering?"

"Jongelui, Maria zegt, zegt, zégt toch iets heel anders? Ja, mits, klinkt heel anders dan neen, tenzij."

"Maar pater, als je standpunt zich heeft ontwikkeld van 'ja, mits' naar 'neen, tenzij, dan is dus eigenlijk je standpunt niet veranderd?"

"Ja, mits je een ander standpunt hebt, neen, tenzij je een ander standpunt hebt."

(Holman 2010)

\section{Conclusie}

In dit artikel zijn we ingegaan op beperkingen die aan het gebruik van mits worden opgelegd op grond van de ANS. We stelden vast dat de taalgebruiker zich daar niet veel van aantrekt en dat hij mits nog steeds en vaker dan gedacht gebruikt, dankbaar als die is voor de specifieke 'semantische regelmaat' en syntactische beknoptheid ervan. Het gaat zover dat zelfs in de twintigste eeuw nog weer een nieuwe gebruiksvorm is opgedoken, namelijk het gelexicaliseerde $J a$, mits.

\section{BIBLIOGRAFIE}

VAN DE BEEK, JOHAN (2018). “Ik zou het liefst 'ja, mits' stemmen. Voor 'nee' kies ik niet”. https://www .limburger.nl/cnt/dmf20180319_00057957/ik-zou-het-liefst-ja-mits-stemmen-voor-nee-kies-ik-niet [geraadpleegd 18 juni 2018.

VAN BORK, GERRIT (2012). Algemeen letterkundig lexicon. Leiden: Stichting Digitale Bibliotheek voor de Nederlandse Letteren (DBNL).

BURGER, PETER (1995). “Gaten in de taal”, in: Onze Taal 12, 293-295.

BURGER, PETER (1996). "Gaten in de taal”, in: Onze Taal 6, 154-156.

BURGER, PETER (1997). "Gaten in de taal”, in: Onze Taal 7/8, 182-184.

COCQUYT, BJORN (2003). “Wie leest De Standaard?”. http://www.standaard.be/cnt/dexc21032003_012 [geraadpleegd 17 juni 2018].

DAALDER, SASKIA (2006). "Regelmaat en interpretatie bij mits-constructies in het moderne Nederlands", in: Voortgang 24, 51-60.

DAALDER, SASKIA (2007). "Een blik in het verleden van een voegwoord: mits in zijn functie van voorzetsel in ouder en nieuwer Nederlands", in: Voortgang 25, 401-419.

D'HULSTER, MARJAN (2010). Beeldvorming in De Morgen, Het Laatste Nieuws en Het Nieuwsblad. Over de criminaliteit gepleegd door daders met een vreemde origine en de bestrijding ervan. https://lib.ugent .be/fulltxt/RUG01/001/458/138/RUG01-001458138_2011_0001_AC.pdf.

HAESRYN, WALTER e.a. (1997). Algemeen Nederlandse Spraakkunst. http://ans.ruhosting.nl/e-ans /index.html [geraadpleegd 21 augustus 2015]. 
TAALADVIES.NET: Mits (als voorzetsel). http://taaladvies.net/taal/advies/vraag/554 [geraadpleegd 18 juni 2018].

TAALTELEFOON: mits (betekenis, synoniem). https://www.taaltelefoon.be/mits-betekenis-synoniem [geraadpleegd 18 juni 2018].

THIJS, BARTIE (2017). "Mits betaelende den tol daertoe staande; een verkenning van de constructie mits + participium presentis in het Nederlands van 1490-1670". https://dokupdf.com/download /mits-betaelende-den-tol-daartoe-staendepdf-_5a39b714d64ab2a614de186b_pdf.

\section{VINDPLAATSEN VAN DE AANGEHAALDE MITS-CONSTRUCTIES}

ANON. (1807). Decreten en Besluiten van Z. Maj. den koning van Holland van 9 Junij 1806 tot 30 dec. 1807. Volume 7.

ANON. (1913). "Iets over en voor onze Katholieke bibliotheken", in: De Tijd: godsdienstig-staatkundig dagblad.

ANON. (1945). "De vos verliest wel zijn haren maar niet zijn streken", in: Ons Volk: den vaderlant ghetrouwe.

ANON. (2012). Bankbeleggen hypotheek. Hypothekenlink. http://www.hypothekenlink.nl/hypotheekvormen-hypotheek-soorten/bankbeleggen-hypotheek-bankbeleggen-hypotheken-bew.html [geraadpleegd 18 juni 2018].

ANON. (2017). "De 'Ja, mits' - cultuur toetsen aan de hand van een casus", in: Platform Gemeenten van de Toekomst. https://www.gemeentenvandetoekomst.nl/themas/fysieke-leefomgeving/artikel /de-ja-mits-cultuur-toetsen-aan-de-hand-van-een-casus/ [geraadpleegd 18 juni 2018].

BOGAERTS, TINE (2018). "RPM in België gebombardeerd tot 'het nieuwe kartel' voor ondernemingen. Wat is RPM eigenlijk?", in: Monard Law. https://www.monardlaw.be/fr/home/-/asset _publisher/3DwqCLLTN4YX/content/rpm-in-belgie-gebombardeerd-tot-het-nieuwe-kartel-voor -ondernemingen-wat-is-rpm-eigenlijk-/maximized [geraadpleegd 18 juni 2018].

C\&P FURNITURE: "Algemene voorwaarden". https://cp.furniture/nl/terms-and-conditions [geraadpleegd 18 juni 2018].

HERMES, JOHANN (1779). Sophia's reize van Memel naar Saxen, Amsteldam: A. E. Munnikhuisen.

HOLMAN, THEODOR (2010). “Ja, mits, neen, tenzij”, in: Het Parool.

HOOGENBIRK, ADOLF JACOB (1922). "Mengelwerk. Bij God verkoren.”, in: De Grondwet.

KRANENBURG, MARK (1999). "Tussen nee tenzij en ja mits", in: NRC. https://www.nrc.nl /nieuws/1999/10/14/tussen-nee-tenzij-en-ja-mits-7466268-a1074629 [geraadpleegd 18 juni 2018].

LEEFKENS, GERHARD (1840). Catechismus over het burgerlijk regt, Amsterdam.

LIPS, TON (2015). "Cursussen / clinics". http://www.lolpassiebiking.nl/cursussenclinics.html [geraadpleegd 18 juni 2018]

PROTESTANTSE, KERK ed. (2016). Toolkit Handleiding oprichten kerkelijk noodfonds.

RAMDHARIE, STIEVEN (2015). "Ja, Trump kan winnen mits hij het spel heel slim speelt", in: De Volkskrant. https://www.volkskrant.nl/nieuws-achtergrond/ja-trump-kan-winnen-mits-hij-het-spel-heel -slim-speelt bb672c37/ [geraadpleegd 18 juni 2018].

VAN ROSSUM, MARTIJN (2017). “Ja, mits' bij uitbreiding in Overijssel”, in: Nieuwe Oogst. https://www .nieuweoogst.nu/nieuws/2017/06/09/ja-mits-bij-uitbreiding-in-overijssel [geraadpleegd 18 juni 2018].

VAN SCHELVEN, GERRIT (1912) (red.). "Historische Schetsen uit het Koloniale Leven" in: De Grondwet.

SOMMER, MARTIN (2010). "Van ja mits naar nee tenzij” in: De Volkskrant. https://www.volkskrant.nl /politiek/van-ja-mits-naar-nee-tenzij a1019817/ [geraadpleegd 18 juni 2018].

STASSEN, ELSBETH (2011). “Doden van dieren: ja, mits ...., of nee, tenzij ....?” https://www.wur.nl/en /Publication-details.htm?publicationId=publication-way-343133333337 [geraadpleegd 18 juni 2018].

VAN WIJCK, FRANK (2017). "Ja mits." in: Arts en Auto. https://www.artsenauto.nl/ja-mits/ [geraadpleegd 18 juni 2018]. 


\title{
MITS SE STÁVÁ ČíM DÁL POPULÁRNĚJŠÍ. LEXIKALIZOVANÉ
} JA, MITS JAKO NOVÁ GRAMATICKÁ KONSTRUKCE

Mluvnice a stylistické př́ručky omezují použití mits (pokud) na několik gramatických konstrukcí. Uživatelé jazyků na tato omezení nedbají a mají tendenci užívat jich odlišně, ale vždy s ohledem na sémantickou správnost popsanou Saskií Daalderovou: mits $p, q(q=$ požadovaný stav, pro který $p$ = conditio sine qua non). Ve 20. století vzniká nová konstrukce: lexikalizované Ja, mits.

\author{
Gert Loosen \\ Debreceni Egyetem \\ E-mail: gertloosen@gmail.com
}

